\title{
When do Followers Perceive Their Leaders as Ethical? A Relational Models Perspective of Normatively Appropriate Conduct
}

\author{
Natalija Keck ${ }^{1,2,3} \cdot$ Steffen R. Giessner ${ }^{1}$ Niels Van Quaquebeke ${ }^{2}$ Erica Kruijff ${ }^{4}$
}

Received: 28 February 2018 / Accepted: 28 October 2018 / Published online: 17 November 2018

(c) The Author(s) 2018

\begin{abstract}
In the aftermath of various corporate scandals, management research and practice have taken great interest in ethical leadership. Ethical leadership is referred to as "normatively appropriate conduct" (Brown et al. in Organ Behav Hum Decis Process 97(2):117-134, 2005), but the prescriptive norms that actually underlie this understanding constitute an open question. We address this research gap by turning to relational models theory (Fiske in Structures of social life: the four elementary forms of human relations, Free Press, New York, 1991), which contextualizes four distinct moralities in four distinct interactional norms (i.e., the relational models). We expect that the norms inherent in each model dictate the type of leader relationship that followers deem ethical. Specifically, we hypothesize that, for each norm, followers will perceive leaders as less ethical the more discrepant, i.e., the more incongruent, followers' ideal relational norm is with the perceived norm that they attribute to their actual leader-follower interaction. We tested the respective incongruence hypothesis in a cross-sectional survey of 101 Dutch employees. Polynomial regression and surface response analyses provide support for the hypothesized incongruence effects in each of the four relational models, suggesting that normatively appropriate conduct should not be limited to caring (i.e., community-oriented) behaviors. Indeed, all four relational models can predict ethical leadership perceptions. We discuss the implications in the context of ethical leadership research and managerial practice.
\end{abstract}

Keywords Congruence $\cdot$ Ethical leadership $\cdot$ Polynomial regression analysis $\cdot$ Relational models

Electronic supplementary material The online version of this article (https://doi.org/10.1007/s10551-018-4055-3) contains supplementary material, which is available to authorized users.

Natalija Keck

natalija.keck@uni-hamburg.de

Steffen R. Giessner

sgiessner@rsm.nl

Niels Van Quaquebeke

niels.quaquebeke@the-klu.org

Erica Kruijff

erica.kruijff@eriks.nl

1 Department of Organisation \& Personnel Management, Rotterdam School of Management, PO Box 1738, 3000 DR Rotterdam, The Netherlands

2 Department of Management \& Economics, Kuehne Logistics University, Großer Grasbrook 17, 20457 Hamburg, Germany

3 Present Address: Industrial \& Organizational Psychology, University of Hamburg, Von Melle Park 5, 20146 Hamburg, Germany

4 Rotterdam, The Netherlands
With corporate fraud and corruption scandals making the headlines, corporate leaders have come under increasing pressure to reinforce business ethics (e.g., Mukherjee 2016; Sherman 2017). In their roles as strategic decision-makers and representatives of company values, ethical leaders are expected to define, exemplify, and promote ethical standards to their employees through their words and deeds (e.g., Treviño et al. 2003). However, we also know that leadership is partly constructed in the mind of the follower (Hernandez and Sitkin 2012; Lord and Maher 1991/2002; Meindl 1995); in this regard, a leader's ethical intentions may not fit a follower's individual conception of ethical leadership. For instance, in an effort to keep the organization profitable, a leader may consider it a necessary and morally appropriate business practice to cut personnel costs via temporary work contracts. On the other hand, employees may regard such actions as a violation of the employer's duty to show loyalty and care, hence exploitative and morally inappropriate. Whether an interaction is perceived as ethical seems to depend on the relational normset that individuals refer to in the present situation. Thus, the question arises: What 
are the normsets that constitute ethical leadership and what role does the relational context play herein? In short, when do followers perceive their leaders as ethical and when they do not?

In organizational research, a highly influential conception of ethical leadership stems from Brown and colleagues (2005). Drawing on social learning theory, Brown and colleagues conceptualize ethical leadership as "normatively appropriate conduct" (2005, p. 120). Their work has formed the starting point for many leadership studies with a focus on ethics. Numerous empirical studies have demonstrated a positive impact of ethical leadership, e.g., on employee deviance, as well as their perceptions of distributive justice and ethical climate (for recent meta-analyses see Bedi et al. 2016; Hoch et al. 2016; Ng and Feldman 2015). Nonetheless, Brown and colleagues' conceptualization has also been widely criticized for being too vague to work with (Giessner and Quaquebeke 2010; Hannah et al. 2014; Hoch et al. 2016; Tenbrunsel and Smith-Crowe 2008) as the authors do not determine the form and nature of morality underlying ethical leadership. Despite subsequent studies' efforts for clarification (Eisenbeiss 2012; Kalshoven et al. 2011; Resick et al. 2006; Riggio et al. 2010), to date, no effective framework has been formulated to explain individual and contextual differences in ethical leadership evaluations. This raises a question about the validity of a normative foundation.

In order to delineate the normative foundation of ethical leadership, Giessner and Van Quaquebeke (2010) proposed a relational framework that the present study elaborates on and empirically supports. They rely on relational models theory (Fiske 1991; Haslam 2004) mainly for two reasons: First, it provides a comprehensive and exhaustive taxonomy of social relations and may therefore offer meaningful insights into the dynamics of follower-leader interactions. Second, it prescribes coordination norms to each postulated relationship type (i.e., the relational models: communal sharing, authority ranking, equal matching, and market pricing), and in this way defines the boundaries of acceptable moral behavior (Giessner and Quaquebeke 2010; Rai and Fiske 2011). The authors assume that followers coordinate and evaluate interactions with their leaders according to the four relational models - or more precisely, accordingly to the moral normsets inherent to each relational model.

Building on Giessner and Van Quaquebeke (2010), we outline the RMT as a contextualized moral framework in which follower-leader interactions need to suit the morality of the given relationship type in order to be judged ethical. Based on implicit leadership theories, we argue that followers hold expectations about the ideal shape of their leader-follower interaction. Consequently, ethical leadership perceptions will depend on the overlap between followers' ideal expectations (i.e., the normset followers hold appropriate for the given interaction) and their perceptions of the actual leader-follower interaction (i.e., the normset they prescribe to the interaction). In other words, we predict that higher discrepancies (i.e., incongruence) between followers' ideal and current relational models will lead followers to appraise their leaders as less ethical. We test our incongruence hypothesis by applying polynomial regression and response surface analyses to a cross-sectional sample. By testing whether each moral normset (i.e., each relational model) may serve as a reference framework for ethical leader evaluations, we are able to scrutinize Brown and colleagues' key assumption about the normative nature of ethical leadership.

In sum, our study advances ethical leadership research in manifold ways. First, we seek to underpin Brown and colleagues' definition of ethical leadership with a framework that is soundly rooted in social relationship research. Second, our investigation lends strong support to the notion that ethical leadership is not a behavioral prescription, but a perception phenomenon. Lastly, our research emphasizes that followers construe ethical leadership based on the fit between relational framings. Our investigation nuances overly simplistic recommendations about solely bolstering leaders' caring behaviors; instead we argue that leaders must actively engage with followers' expectations in order to be perceived ethically.

\section{Ethical Leadership as Normatively Appropriate Conduct}

Despite the lack of consensus about the definition of ethics or morals (cf. Haidt 2008; Tenbrunsel and Smith-Crowe 2008), it is indisputable that they pertain to socially accepted principles of how people relate to each other (Gini 1997; Haidt 2008). For instance, Toffler (1986) describes ethics as "rules or standards" that "govern behaviors," involving the kind of morals (i.e., principles of right and wrong) that individuals and groups deem appropriate (p. 10). Speaking of leadership in terms of interpersonal influence (e.g., Yukl 2002) thus invariably links leadership to ethical concerns (Ciulla 1995; Hoch et al. 2016; Northouse 2010). In order to be effective, i.e., for a leader's influence being accepted, leaders must know how to relate to their followers in an appropriate way (Hernandez and Sitkin 2012).

In order to account for the central role of ethics in leadership, Brown and colleagues (2005) developed the construct of ethical leadership. They define ethical leadership as "the demonstration of normatively appropriate conduct through personal actions and interpersonal relationships, and the promotion of such conduct to followers through two-way communication, reinforcement, and decision-making" (2005, p. 120). Drawing on a social learning perspective (Bandura 1977, 1986), the authors envisioned ethical leaders acting as 
role models to subordinates (Brown et al. 2005). By rewarding appropriate and disciplining inappropriate conduct, leaders inform followers about an organization's expected behaviors; by embodying ethical standards themselves, leaders encourage emulation.

Their ethical leadership scale (ELS; Brown et al. 2005) is the most commonly used operationalization in ethical leadership research thus far. Herein, Brown and colleagues (2005) chose a descriptive approach. Based on interviews and literature research (Brown et al. 2005; Treviño et al. 2003), ELS describes expectations of leader behavior while leaving the nature and number of moralities that constitute appropriate leader conduct to rater's individual perspective. Brown and colleagues argue "what is deemed appropriate behavior is somewhat context dependent" (2005, p. 120) and thus take a relativistic position on the definition on appropriateness.

Brown and colleagues' (2005) work quickly garnered scientific interest and prompted numerous studies. Empirical studies have found that ethical leadership has a positive impact on followers' attitudes (e.g., supervisor satisfaction) and behaviors (e.g., counterproductive work behavior), on relational outcomes (e.g., leader effectiveness; see recent meta-analyses by Bedi et al. 2016; Hoch et al. 2016; Ng and Feldman 2015), firm performance (Eisenbeiss et al. 2014), and on management level (Mayer et al. 2009). Comparative meta-analyses further highlight that, in ethics-related outcomes, ethical leadership exhibits incremental validity over alternative leadership styles and concepts (e.g., transformational leadership, interactional fairness; Hoch et al. 2016; $\mathrm{Ng}$ and Feldman 2015).

Naturally, the proliferation of interest in Brown and colleagues' (2005) work has invited some criticism. One major concern lies with their descriptive approach to defining ethical leadership (Eisenbeiss 2012; Giessner and Quaquebeke 2010; Hannah et al. 2014; Hoch et al. 2016). Critics argue that research "has provided little prescriptive information as to the specific nature and forms of ethical behaviors" (Hoch et al. 2016, p. 24). ELS items describing the leader as someone who "has the best interests of employees in mind" and "conducts his/her life in an ethical manner" (Brown et al. 2005 , p. 126) are not specific enough to guide leaders in being ethical. Even worse, under the cloak of subjective ethicality, ELS items do not necessarily exclude dysfunctional behaviors (Hannah et al. 2014).

In an attempt to address this critique, subsequent studies tried to add a normative component to ethical leadership research by drawing upon a behavioral, characterological or value-driven approach (Eisenbeiss 2012; Kalshoven et al. 2011; Resick et al. 2006; Riggio et al. 2010). Respective studies conjecture that an ethical leader is characterized by the presence of a set of behaviors, traits, or values. These efforts have generated more concrete material to work with, but simultaneously invited significant concerns. Specifically, just as with the ELS, the resulting ethical leadership measures seek to represent a norm by compiling behaviors, traits, or values (derived from various literature and interviews) into a full range of ethical leader conduct. In fact, however, they reflect a set of expectations about good leader qualities selected by the researchers. None of the ethical leadership measures is based on a comprehensive and exhaustive theoretical framework of norms. By implication, a leader who does not exhibit the hypothetical full range would appear less ethical. Yet, as Brown and colleagues (2005) acknowledge, there are individual and contextual differences about what constitutes morally right and appropriate leader conduct. Indeed, empirical research supports this assumption by showing variations in ethical behavior within and across groups, cultures, and societies (Parsons and Shils 1951; Power et al. 1989; Resick et al. 2006; Selznick 1992). Existent ethical leadership measures provide us with a fairly limited understanding of individual and contextual differences that may render certain leader behavior more or less appropriate resulting in a biased view on the phenomenon. Moreover, as the measures generally do not rely on a theoretical framework of norms, there is an open question about whether the key assumption - that ethical leadership comprises normatively appropriate behavior-is valid.

Part of the issue for these studies is that they follow a leader-centric approach; as such, they focus on leader behaviors and attributes as perceived by their followers. Yet, Brown and colleagues (2005) refer to ethical leadership as a "two-way communication" (p. 120): a process between follower and leader in which interpersonal relations play a vital role. Recent accounts in leadership research support a relational understanding of leadership stressing that it is a socially constructed process to which leaders and followers mutually contribute (e.g., Huang et al. 2008; Van Gils et al. 2010). Hence, leader-centric studies tell only one side of the story and therefore cannot embrace the entire complexity of ethical leadership. In order to understand the normative foundation of ethical leadership, we need to understand the basic kind of social relationships follower and leader engage in.

\section{Relational Models Theory as a Contextualized Moral Framework}

One exhaustive, yet concise framework for studying social structures is the relational models theory (RMT; Fiske 1991; Haslam 2004). Based on classical social psychological and anthropological research (see Fiske and Haslam 2005 for a detailed review), RMT identifies and describes four cognitive schemas-the relational models (RMs) communal sharing, authority ranking, equal matching, and market pricing - that people use in order to structure their manifold 
social interactions. RMs integrate social cues, help to make sense of human behavior, and offer guidance when establishing and evaluating appropriate conduct. They rely on binding rules in order to generate and maintain cooperative relationships. In a nutshell, RMs are "shared [mental] models of how people should coordinate with each other" (Fiske and Haslam 2005, p. 267).

It is important to note that each RM comes with a distinct normset (Fiske 1991). As such, each RM is assumed to work as a reference framework for most social-relational cognition, including moral judgment. Fiske (1991) claims that most moral imperatives derive from the four RMs, as they capture the social rules that people regard as obligatory. In support of his claim, Fiske $(1991,1992)$ reviewed principal research (including the landmark scholarship of Piaget 1932/1973; and Weber 1922/1978) in order to establish links between each relational structure and ethically relevant social phenomena. Fiske (1992) concluded that, because each relationship type entails specific obligations, the coordination norms of each RM are internally perceived as fair and legitimate in making a relationship work. In the following, we will briefly characterize each RM as postulated by Fiske (1991). Herein, we will focus on the underlying morality:

Communal sharing (CS) interactions are structured with respect to equivalence, i.e., whether people share a common substance or are on the same team. The model involves a morality that is best described as a "one-for-all and all-forone" morality (Giessner and Van Quaquebeke 2010, p. 46). It is considered morally correct, fair, or just if members of this relationship take according to their needs and give according to their abilities. CS interactions are often characterized as loving, altruistic, and caring. Fiske (1991, 1992) builds the CS morality on social phenomena such as altruism (Blum 1987), in-group favoritism (Tajfel 1982), commitment to loving relationships (Gilligan 1982), and distribution according to need in justice research (e.g., Tindale and Davis 1985).

Authority ranking (AR) interactions are structured with respect to ordered differences along a hierarchical social dimension, such as professional standing in a company. The model involves a morality that is best described as a "noblesse oblige" morality (Giessner and Van Quaquebeke 2010, p. 46), in which those in power are compelled toward directive guidance and social responsibility. People consider AR interactions to be morally correct, fair, or just if higher-ranked individuals receive a larger share of resources, respect, and loyalty as long as they accept responsibility over lower-ranked individuals whom they guide, instruct, and protect. Fiske (1992) builds the AR morality on social phenomena such as religious devotion, children's conception of rules (Piaget 1932/1973), and moral attributions to authority roles (Hamilton 1978).
Equal matching (EM) interactions are structured with respect to uniform contributions and balanced reciprocities. The model involves a morality that is best described as a "tit for tat" morality (Giessner and Van Quaquebeke 2010, p. 46), in which people keep track of imbalances, engaging in both positive and negative reciprocities (e.g., revengeful actions). The unit of exchange plays a major role in this model: Any accepted favor appears as morally correct, just, or fair so long as it is repaid by an action of similar value. It is the perceived value that counts and not the actual difference in value. Fiske (1991) builds the EM morality on ultimatum bargaining research (Guth et al. 1982), the equality principle in distributing rewards (e.g., Tindale and Davis 1985), and Rawls' (1971) theory of justice, among other examples.

Market pricing (MP) interactions are structured with respect to ratios of a previously negotiated utility metric, such as with prices. The model involves a morality that is best described as a "greatest goods for the wealthiest" morality (Giessner and Van Quaquebeke 2010, p. 46). All relevant features and components of the relationship are reduced to the proportionality of a socially meaningful utility metric. In short, what matters is how much you get in exchange for your input. Interactions are considered to be morally correct, just, or fair if they follow previously agreed rules based on cost-benefit calculations, such as in employment contracts. Fiske (1991) builds the MP morality on principles of meansends efficiency (Weber 1922/1978), equity theory (Adams 1965), achievement motivation (McClelland 1961/1976), and moral commitments in social contract theories (e.g., Hamilton 1978), among other examples.

RMT has found considerable empirical evidence in both quantitative and qualitative research across cultures and research fields, including organizational behavior (for an overview see Haslam 2004; for a more comprehensive bibliography, see http://www.rmt.ucla.edu). Research supports the number of proposed mental models, their discreteness and coherence, as well as their relevance in everyday social cognition (e.g., Fiske et al. 1991; Fiske and Haslam 1997; Haslam and Fiske 1992). Herein, several studies investigated the link between RMs and fairness perceptions (Connelley and Folger 2004; Fiddick and Cummins 2007; Goodnow 1998).

According to Fiske (1992), people prescribe RMs to their relationships with interaction partners based on specific aspects of their interactions and meaningful individual attributes that capture their attention. Consequently, it is possible that a follower construes the follower-leader relationship along a different RM than the leader or an observer would do. As a prescriptive moral framework, RMT not only accounts for individual differences in moral conception-it also illuminates the contexts in which a particular morality becomes most appropriate (Rai and Fiske 2011). In that vein, 
Rai and Fiske (2011) argue that there is no such thing as universally fair actions: "any given action will be judged as right, just, fair, honorable, pure, virtuous, or morally correct when it occurs in some social-relational contexts and will be judged as wrong when it occurs in other social-relational contexts" (p. 57). They stress that context wields serious influence over nearly every aspect of social behavior and cognition-moral cognition is no exception. Reviewing examples from social, cognitive, and evolutionary psychology, the authors argue that morality is inseparable from the relational context in which it takes place as its function lies in the "generation and maintenance of long-term socialcooperative relationships with others" (p. 59). As each RM involves a morality that is embedded in the respective relational structure, Rai and Fiske (2011) advocate that RMT can be an effective contextualized moral framework. Consequently, the relational structure between two interactants determines the kind of morality that is deemed appropriate.

Contextual differences are accounted for inasmuch as according to RMT, people do not exclusively use a single mental model for their relationship with an interactant (Fiske 1991; Haslam 2004). For instance, one can follow an AR relationship with the supervisor for performance reviews, a CS relationship for brainstorming meetings and carpool to work with that person based on an EM principle. Nonetheless, Fiske (1991) assumes that one predominant RM will characterize a given relationship, with other RMs being nested within. Moreover, the same behavior can indicate different RMs depending on the context. For instance, within a team-centric culture, helping out a teammate at work may be a duty and therefore seen along the MP schema. However, helping the same person outside of work may follow a different relational schema, such as EM that obliges individuals to return favors.

\section{Relational Models Theory to Understand Normatively Appropriate Leader Conduct}

In their theoretical paper, Giessner and Van Quaquebeke (2010) propose that RMT's prescriptive moral framework and contextual flexibility can be used to develop a better understanding of normatively appropriate conduct in ethical leadership. The authors reason that, although ethical leadership research has mainly relied on leader characteristics that fall within a CS framework, each RM may serve as a reference framework to ethical leadership.

The predominance of the CS framework is clear in the literature: In Brown and colleagues' ELS (2005), ethical leaders are supposed to show care and concern, "listen to what employees have to say" and have "the best interests of employees in mind" (p. 126); transformational leaders are supposed to respond to followers' individual needs (Bass
1985; Burns 1978); servant leaders are supposed to show empathic, caring, and team-building behaviors (Greenleaf 1977; Liden et al. 2008). However, caring and considerate behavior may not appear appropriate to everyone and in every given context. For instance, attending to the needs of a working single parent may appear fair to the single parent, but unfair to team members who value equal treatment. In times of crisis, a directive and authoritarian leader may be perceived as more appropriate than a leader who is primarily concerned with pleasing everybody's needs. Giessner and Van Quaquebeke (2010) conclude that the considerate and caring leader is largely overestimated in the ethical leadership literature and give examples of how each RM morality can be linked to ethical leadership.

According to the social learning perspective (Bandura 1977, 1986), ethical leaders are supposed to function as role models (Brown et al. 2005). In their higher-ranked position, leaders are assigned the power to control resources and affect followers' behavior. However, an ethical leader is expected to use this power responsibly and model ethical behaviors to trigger emulation processes in followers. This accords with the "noblesse oblige" morality inherent in the AR model (Giessner and Van Quaquebeke 2010). Furthermore, Brown and colleagues (2005) describe the leader-follower relationship in terms of social exchange. Social exchange relationships typically depend on norms of reciprocity (Gouldner 1960): By offering fair and caring treatment beyond what is mandated, leaders are thought to encourage beyond-the-callof-duty behavior in followers (Brown and Treviño 2006). Such a "tit for tat" morality is reflected in the EM model (Giessner and Van Quaquebeke 2010). Lastly, Giessner and Van Quaquebeke (2010) argue that the "greatest goods for the wealthiest" morality, inherent in the MP model, permeates capitalistic contexts. Herein, interactants strive to maximize their gain when negotiating their input-output ratio, such as in employment contract negotiations. The focus on personal gain may explain why this morality has rarely been linked to ethical leadership literature. However, studies show that employees feel morally obliged to fulfill the requirements of their employment contracts and judge incompliance with job descriptions as inappropriate (cf. Fiske 1991, 1992). Thus, MP standards seem to be highly relevant to everyday working life (Giessner and Van Quaquebeke 2010).

In the present study, we follow Giessner and Van Quaquebeke's (2010) proposition and empirically test whether all four RMs (CS, AR, EM, and MP) may constitute ethical leadership norms. To do so, we model followers' cognitive evaluation processes and probe whether followers make use of each RM reference framework in their leader evaluations. We chose a follower-centric approach, as Brown and colleagues (2005) regard followers' individual perceptions as crucial to ethical leadership. 
From a follower-centric RMT perspective (Fiske 1991), ethical leadership refers to a follower-leader relationship that is coordinated according to the norms that followers consider appropriate. In line with Brown and colleagues' relativistic view on appropriateness (2005), we assume that followers show individual differences regarding what norms they deem appropriate for their relationship with their leader. We also assume that followers may hold more than one RM appropriate as they experience their leader in diverse context at work. This assumption finds support in RMT, which posits that people do not exclusively use a single RM for an interactant (Fiske 1991; Haslam 2004). For this reason, we chose a within study design asking each respondent about each RM.

As neither the ethical leadership theory (Brown et al. 2005) nor RMT (Fiske 1991) detail the cognitive processes of moral judgment, we draw on the processes described for implicit leadership theories (ILTs; Lord et al. 1984; Van Quaquebeke et al. 2014) to substantiate our research. In leadership literature, ILTs offer a valuable means to understand how individuals make sense of social context and form leader evaluations. Through socialization and past experiences with leaders, followers are assumed to develop cognitive schemas, i.e., knowledge structures about what a leader should be like (Foti and Lord 1987; Lord and Shondrick 2011). The mechanism behind leader evaluations is described as a match-based process, resulting from a perceived fit of followers' mentally represented leader schemas, i.e., their leader expectations, and their observations, i.e., their actual leader experience. The more discrepancies there are between the schema and the observation, the less likely it is that followers will categorize the observation into the expected schema and evaluate the leader accordingly.

We applied the match-based process suggested by ILTs to our research in order to examine when followers perceive their leaders as ethical. As such, we assume that followers' ethical leadership perceptions result from a fit of their expected cognitive schemas, i.e., followers' expected RM, and their actual observation, i.e., the RM that they prescribe to their actual leader interaction. In ILT research, expectations are usually operationalized in terms of typical (i.e., most frequent) and ideal (i.e., positively valenced) behaviors (Foti et al. 2017; Van Quaquebeke et al. 2014). As Brown and colleagues (2005) understand appropriateness as a positively valenced judgment, we operationalize followers' RM expectations in terms of their ideal interaction with the leader. Consequently, we asked each study participant to rate for each RM (a) the extent to which the RM represented interaction principles they ideally wished for their relationship with their leader (i.e., ideal RM expectation) and (b) the extent to which the interaction principles actually ruled their leader interaction (i.e., current RM). We predicted the less followers' ideal and current RM will fit, i.e., the higher the incongruence, the less ethical followers will judge their leaders. Higher incongruence may warn followers that their leaders are likely to violate their conceptions of fair treatment. Lower incongruence, on the other hand, may inform followers that their leaders are likely to consider the same coordination norms to be appropriate and play by the same rules. Assuming that each RM may constitute the foundation of ethical leadership, we expect the predicted incongruence effect with each of the four RMs described by RMT. We formulate our hypothesis as follows:

Hypothesis The higher the incongruence between followers' current and ideal relationship with a leader, the less likely followers will perceive that leader as ethical.

We test our incongruence hypothesis using Edwards' polynomial regression approach, which is in line with modern standards in fit research (Edwards 2002; Edwards and Parry 1993).

\section{Method}

\section{Data Collection and Participants}

We aimed at a heterogeneous employee sample to be able to tap various types of follower-leader relationships. For this purpose, snowball sampling is an established recruiting technique (e.g., Morgeson and Humphrey 2006; Zapata et al. 2013). An assistant on the project collected data via online questionnaires and in print. Invitations to participate online were distributed in the assistant's personal network and were further disseminated in a snowball fashion (i.e., participants invited further participants in their network; for similar procedures see Mayer et al. 2009; Morgeson and Humphrey 2006). Paper and pencil questionnaires were distributed on a frequent commuter rail line to Rotterdam. Respondents who reported to be currently employed and subordinated to at least one executive were eligible for participation. Participation was not incentivized.

Bilingual speakers translated the measures (detailed below) from English into Dutch (cf. Brislin 1970). We specifically focused on intraperson data (i.e., single source), as multi-source data measuring a fit of leaders' and followers' RMs can be misleading. According to RMT (Fiske 1991), follower and leader may hold different behavioral implementation rules for the same RM (e.g., due to cultural differences). Thus, followers may misinterpret leaders' actions and judge the leader as inappropriate, even though follower and leader have the same RM in mind. Our sample consisted of 101 employees, i.e., 45 female and 49 male respondents ( 7 respondents did not indicate their gender). Respondents were on average 35.39 years old $(\mathrm{SD}=13.28)$ with an average of 
14.71 years of work experience $(\mathrm{SD}=11.8)$ and 4.04 years of working experience with their leader $(\mathrm{SD}=6.01)$. Half of the sample indicated that their leader was responsible for at least 15 employees, ranging from 1 to 3000 employees. Nine respondents indicated to be working in the manufacturing industry.

\section{Measures}

We informed participants that the survey's intent was to uncover a better understanding of the relationships between leaders and their followers. We assured respondents that their data would be treated confidentially and anonymously. In order to guard against selective operationalization, we assessed the predictors by using two variants of the measures: RM vignettes and RM scale. Following the RM measures, we assessed the outcome variable 'perceived ethical leadership,' along with demographic variables.

\section{RM Vignettes}

This measure comprised four vignettes (see "Appendix"), each containing a one-paragraph descriptive summary of an RM. We adopted the vignettes from Haslam and Fiske (1992), who used them to categorize relationships and acquaintances in several empirical studies. The vignettes were presented unlabeled to the study participants (i.e., the specific RM behind each vignette was not explicitly stated). For each vignette, we instructed respondents to indicate (a) how much the description applied to their ideal relationship with their leader and (b) how much the description applied to their current relationship with their leader, both on a 7-point Likert scale ranging from 1 (=not at all) to 7 (=fully). We explained that "ideal relationship" stood for the kind of relationship that respondents would personally wish for with their leader. "Current relationship" stood for the kind of relationship that respondents believed that they currently have with their work leader.

\section{Vignettes Choice Measure}

At the end of the RM vignettes measure, we asked respondents to indicate which of the four previously described relationships, in their view, best represented their (a) ideal and (b) current relationship with their leader. This explorative choice measure assessed the perceived importance of one RM over the others (i.e., the perceived predominant RM in a follower-leader relationship). As such, the vignettes choice measure captures whether followers systematically prefer the CS "one-for-all and all-for-one" morality over other RM moralities in a follower-leader relationship, which would support the literature's image of an ethical leader as one who is caring and attentive.
Note that the vignettes choice measure does not supply enough information to test our hypothesis. Predominant RMs do not accurately describe a follower-leader relationship; they rather reflect typical interactions. However, there might be situations in a follower-leader relationship that invoke a different relational structure. It might be those rare, but personally relevant situations - untapped by predominant RMs - that have a strong effect on followers' ethical leadership judgment. To address this issue, we assessed both the between-RM vignettes choice measure and the withinRM measures (i.e., RM vignettes and RM scale, in which followers rated their leaders on each RM).

\section{RM Scale}

We adapted Vodosek's (2009) 18-itemed scale (adjusting it from team focus to leader focus) that assesses the four RMs with a subscale each. In his study, Vodosek (2009) has demonstrated validity and reliability for the RM scale by showing acceptable results for confirmatory factor analyses in a cross-validated sample. As in the RM vignettes, we instructed respondents to indicate (a) how often the statement applied to the current relationship with their leader and (b) how often the statement should be true in an ideal relationship with their leader. All items were measured on a 5-point Likert scale from 1 (=none of the time) to 5 (=always). The current and ideal CS relationships were assessed with 5 items each (e.g., "If my leader or I need something, we give it to each other without expecting anything in return"), as were the current and ideal EM relationships (e.g., "My leader and I often take turns in doing things"). The current and ideal AR relationships were assessed with 4 items each (e.g., "My leader makes the decisions and I generally go along"), as were the current and ideal MP relationships (e.g., "My leader and I make decisions according to the ratio of benefits and costs for each of us.").

\section{Ethical Leadership}

To measure perceived ethical leadership, we employed the ELS by Brown and colleagues (2005). ELS comprises 10 items, such as "My leader disciplines employees who violate ethical standards" or "My leader discusses business ethics or values with employees." Participants' responses were assessed on a 5-point Likert scale from 1 (= strongly disagree) to 5 (= strongly agree). Before respondents completed the items, we explicitly instructed them to think of the same leader that they considered for the RM measures. 


\section{Analytic Strategy}

We utilized polynomial regression and response surface analysis to test our incongruence hypothesis (Edwards 2002; Edwards and Parry 1993). Polynomial regression analysis is common in fit research and has replaced the use of difference scores over the past decade (Edwards 2002). It relies on quadratic regression equations that serve as unconstrained equations for squared difference scores (e.g., Euclidean difference score). This allows for more reliable and precise outcome predictions at each combination of the two predictor variables (Edwards 2002). Meanwhile, response surface analysis is typically used to visualize and evaluate polynomial regression results. Following Edwards' recommendations (Edwards and Parry 1993), we scale-centered our predictor variables at their scale-midpoint (i.e., 4 with the RM vignettes and 3 with the RM scale) prior to regression analysis in order to facilitate the interpretation of results. For each RM measure (i.e., RM vignettes and RM scale) and each RM (i.e., CS, $\mathrm{AR}, \mathrm{EM}$, and MP), we estimated the following equation in which C stands for followers' self-reported current relationship with the leader, I stands for followers' self-reported ideal relationship with the leader, and EL stands for the outcome, followers' perceived ethical leadership:

$\mathrm{EL}=b_{0}+b_{1} C+b_{2} I+b_{3} C^{2}+b_{4} \mathrm{CI}+b_{5} \mathrm{I}^{2}+e$.

This resulted in eight estimated equations. We used the $\mathrm{R}$ package RSA (Schönbrodt 2015) to estimate the regression coefficients, test for model significance, retrieve the relevant surface indicators (Table 2), and plot three-dimensional surface charts that describe the nature of the examined empirical relationship (Fig. 1). The hypothesis testing includes robust errors due to polynomial regression equations encompassing non-parametric squared terms (Schönbrodt 2015).

We predicted that higher incongruence between followers' ideal and current RMs relates negatively to followers' ethical leadership perceptions. A significant and negative curvilinear slope along the incongruence line (i.e., $I=-C$ ) would support our hypothesis. The curvilinear slope is the key indicator of incongruence effects (Shanock et al. 2010), as it "captures how the degree of incongruence between the two predictor variables may influence the outcome variable" (p. 546). In our case, the surface along the incongruence line would need to illustrate an inverted $U$-shape. The incongruence line runs from the front corner (e.g., $I=2$ and $C=-2$ ) to the rear corner (e.g., $I=-2$ and $C=2$ ) of the three-dimensional response surface chart. Accordingly, ethical leadership scores are expected to be lower in the area where ideal and current RM scores are maximally incongruent (e.g., $I=2$ and $C=$ -2 as well as $I=-2$ and $C=2$ ). Conversely, higher ethical leadership scores are expected in the area where followers' ideal RMs fit the perceived current RMs (i.e., $I=C$ ). The curvilinear slope is calculated by $a_{4}=b_{3}-b_{4}+b_{5}$ (where $b_{3}$ is the coefficient for $C^{2}, b_{4}$ is the coefficient for the crossproduct of $C$ and $I$, and $b_{5}$ is the coefficient for $I^{2}$ ).

\section{Results}

\section{Descriptive Statistics}

Table 1 reports the mean values, standard deviations, correlations, and reliability estimates for all variables. Two correlational findings suggest construct validity: First, we found significantly positive correlations between corresponding RMs in the two variants of the RM measure (i.e., current RM vignette and current RM scale). Second, within each RM measure (i.e., within RM vignettes and within RM scale), we found the highest positive correlations between current RMs and the corresponding ideal. Moreover, the corresponding RMs within each measure correlate at a moderate level, which suggests that, on average, our respondents work in leader-follower relationships that do not always meet their ideal leader relationship concept.

\section{Hypothesis Testing}

We conducted polynomial regression and response surface analyses to test the incongruence effects of followers' ideal and actual leader relational concepts on followers' perceived ethical leadership (Edwards 2002). We performed the analyses on the individual level. Because we assessed the predictors using two variants of the RM measures, we have reported the results in two corresponding sections. Additionally, for exploratory purposes, we analyzed responses to the vignettes choice measure to assess the perceived importance of one RM over the others.

\section{Results for Vignettes Choice Measure}

We asked respondents to indicate which of the four described RMs corresponded to their actual and ideal relationships with their leader. The majority of the respondents (44\%) identified AR as the predominant current RM, $15 \%$ as CS, $20 \%$ as EM, and $21 \%$ as MP. The responses on ideal RMs were more equally distributed: $30 \%$ of the respondents indicated CS as their ideal leader relationship, 25\% AR, 25\% EM, and 20\% MP. The results support our study purpose by showing that (a) all four RMs seem to exist in followers' construal of their actual relationship with the leader and (b) overall, the morality underlying CS seem to be as desirable to followers as moralities based on AR, EM, and MP. Moreover, $54 \%$ of respondents prescribed a different RM to their ideal leader-follower relationship than to their actual. This is an indicator of incongruence and thus supports the investigation into incongruence effects. 


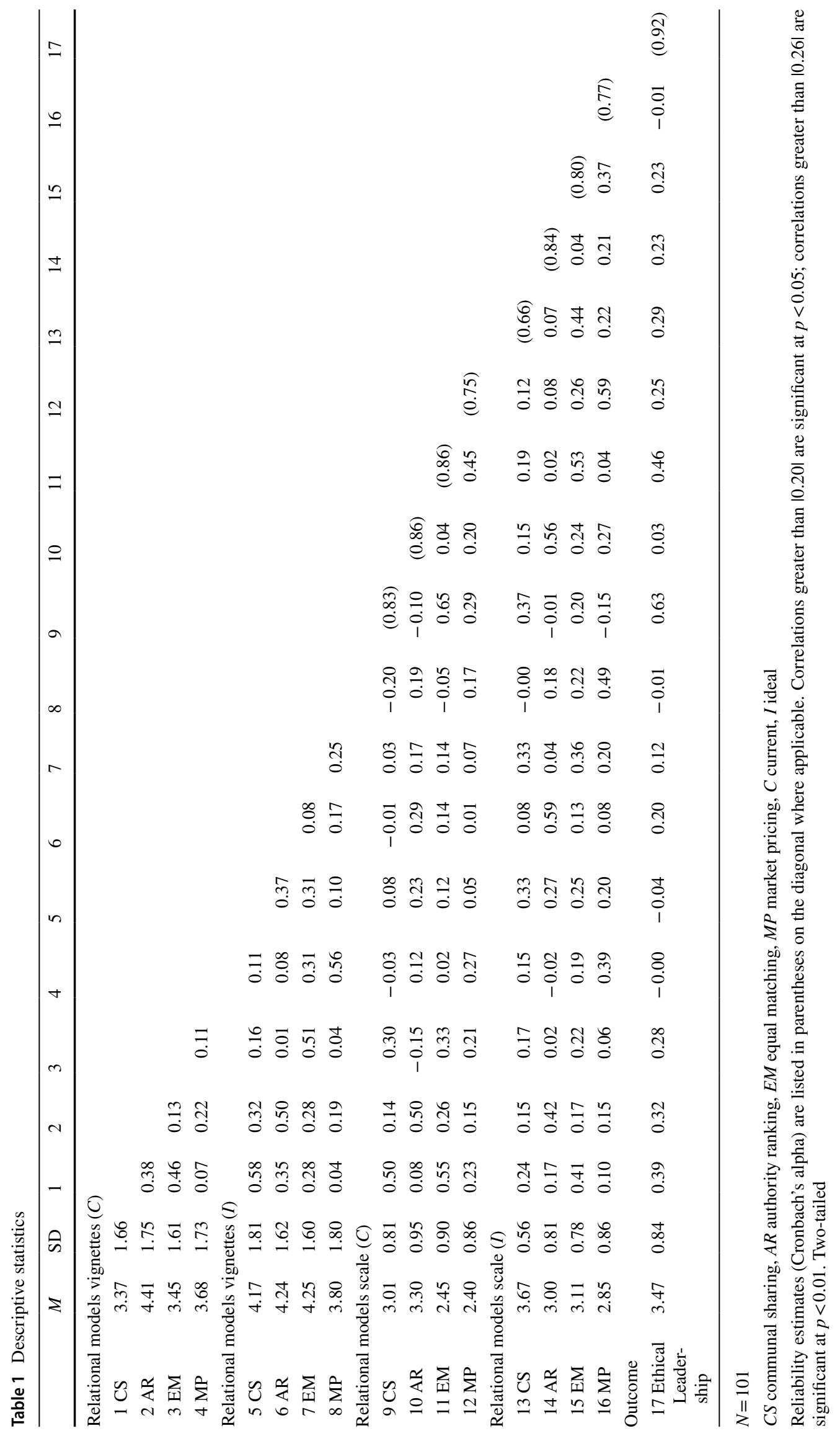




\section{Results for RM Vignettes}

We estimated polynomial regression equations for each RM to test for incongruence effects on followers' ethical leadership perceptions. The results in Table 2 reveal that the five polynomial terms were jointly significant for the CS, AR, and EM models, respectively, explaining 35\% (CS, $p<0.001$ ), 36\% (AR, $p<0.001$ ), and 18\% (EM, $p=0.002$ ) of variance in the outcome. The MP equation explained $9 \%$ of variance in the outcome, but did not reach significance $(p=0.107)$. Thus, the MP coefficients and response surface should be interpreted cautiously (Edwards 2002).

A key indicator of incongruence effects is the curvilinear slope (i.e., $a_{4}$ ) along the incongruence line (i.e., $I=-C$ ) in the three-dimensional response surface chart. We predicted a negative curvilinear slope along the incongruence line: Less convergence between the two predictor variables in the response surface would indicate lower perceived ethical leadership. We used unstandardized polynomial regression coefficients to calculate $a_{4}$ (Table 2). As expected, the curvilinear slopes were significant and negative for each RM equation (CS: $a_{4}=-0.20, p<0.001 ; \mathrm{AR}: a_{4}=-0.25$, $p<0.001 ; \mathrm{EM}: a_{4}=-0.22, p=0.019 ; \mathrm{MP}: a_{4}=-0.15$, $p=0.006$ ).

We then plotted the response surfaces using the estimated regression coefficients. As predicted, all plotted response surfaces showed a downward curvature along the incongruence line (Fig. 1a-d). The level of perceived ethical leadership was lower at both the front corner (i.e., $I=3$ and $C$ $=-3$ ) and the rear corner (i.e., $I=-3$ and $C=3$ ) in all
Table 2 Results of polynomial regression and response surface analysis

\begin{tabular}{|c|c|c|c|c|}
\hline & $\mathrm{CS}$ & $\mathrm{AR}$ & EM & MP \\
\hline \multicolumn{5}{|l|}{ Relational models vignettes } \\
\hline Intercept $\left(b_{0}\right)$ & $3.81(0.10)^{* * *}$ & $3.58(0.11)^{* * *}$ & $3.79(0.12)^{* * *}$ & $3.56(0.10)^{* * *}$ \\
\hline$C\left(b_{1}\right)$ & $0.22(0.05)^{* * *}$ & $0.16(0.04)^{* * *}$ & $0.05(0.08)$ & $<0.00(0.06)$ \\
\hline$I\left(b_{2}\right)$ & $-0.10(0.05)^{*}$ & $0.02(0.05)$ & $0.05(0.09)$ & $0.01(0.06)$ \\
\hline$C^{2}\left(b_{3}\right)$ & $-0.09(0.02)^{* * *}$ & $-0.13(0.02)^{* * *}$ & $-0.10(0.04)^{* *}$ & $-0.08(0.04)^{\dagger}$ \\
\hline$C \times I\left(b_{4}\right)$ & $0.09(0.02)^{* * *}$ & $0.13(0.02)^{* * *}$ & $0.07(0.05)$ & $0.08(0.03)^{* *}$ \\
\hline$I^{2}\left(b_{5}\right)$ & $-0.02(0.02)$ & $0.01(0.02)$ & $-0.04(0.03)$ & $>0.00(0.03)$ \\
\hline$R^{2}$ & $0.35 * * *$ & $0.36 * * *$ & $0.18 * *$ & 0.09 \\
\hline \multicolumn{5}{|l|}{ Congruence line $(I=C)$} \\
\hline Slope $\left(a_{1}\right)$ & $0.11(0.04)^{* *}$ & $0.18(0.05)^{* *}$ & $0.10(0.06)$ & $0.00(0.06)$ \\
\hline Curvature $\left(a_{2}\right)$ & $-0.01(0.03)$ & $0.02(0.03)$ & $-0.07(0.04)^{\dagger}$ & $0.00(0.03)$ \\
\hline \multicolumn{5}{|l|}{ Incongruence line $(I=-C)$} \\
\hline Slope $\left(a_{3}\right)$ & $0.32(0.09)^{* * *}$ & $0.14(0.07)^{\dagger}$ & $-0.00(0.15)$ & $-0.01(0.10)$ \\
\hline Curvature $\left(a_{4}\right)$ & $-0.20(0.04)^{* * *}$ & $-0.25(0.04)^{* * *}$ & $-0.22(0.09)^{*}$ & $-0.15(0.06)^{* *}$ \\
\hline \multicolumn{5}{|l|}{ Relational models scale } \\
\hline Intercept $\left(b_{0}\right)$ & $3.43(0.10)^{* * *}$ & $3.53(0.11)^{* * *}$ & $3.65(0.10)^{* * *}$ & $3.53(0.11)^{* * *}$ \\
\hline$C\left(b_{1}\right)$ & $0.39(0.13)^{* *}$ & $<0.00(0.13)$ & $-0.13(0.09)$ & $0.05(0.14)$ \\
\hline$I\left(b_{2}\right)$ & $0.53(0.20)^{* *}$ & $0.21(0.13)$ & $0.39(0.10)^{* * *}$ & $0.13(0.14)$ \\
\hline$C^{2}\left(b_{3}\right)$ & $-0.19(0.08)^{*}$ & $-0.20(0.11)^{\dagger}$ & $-0.47(0.08)^{* * *}$ & $-0.25(0.10)^{*}$ \\
\hline$C \times I\left(b_{4}\right)$ & $0.32(0.12)^{* *}$ & $0.48(0.16)^{* * *}$ & $0.53(0.08) * * *$ & $0.45(0.15)^{* *}$ \\
\hline$I^{2}\left(b_{5}\right)$ & $-0.34(0.13)^{* *}$ & $-0.10(0.14)$ & $0.09(0.09)$ & $0.03(0.13)$ \\
\hline$R^{2}$ & $0.48 * * *$ & $0.20 * * *$ & $0.38 * * *$ & $0.27 * * *$ \\
\hline \multicolumn{5}{|l|}{ Congruence line $(I=C)$} \\
\hline Slope $\left(a_{1}=b_{1}+b_{2}\right)$ & $0.92(0.23) * * *$ & $0.21(0.12)^{\dagger}$ & $0.27(0.09)^{* *}$ & $0.18(0.08)^{*}$ \\
\hline Curvature $\left(a_{2}=b_{3}+b_{4}+b_{5}\right)$ & $-0.20(0.15)$ & $0.18(0.12)$ & $0.14(0.08)$ & $0.23(0.07)^{* *}$ \\
\hline \multicolumn{5}{|l|}{ Incongruence line $(I=-C)$} \\
\hline Slope $\left(a_{3}=b_{1}-b_{2}\right)$ & $-0.13(0.25)$ & $-0.21(0.23)$ & $-0.51(0.17)^{* *}$ & $-0.09(0.26)$ \\
\hline Curvature $\left(a_{4}=b_{3}-b_{4}+b_{5}\right)$ & $-0.85(0.21)^{* * *}$ & $-0.78(0.32)^{*}$ & $-0.91(0.15)^{* * *}$ & $-0.67(0.30)^{*}$ \\
\hline
\end{tabular}

$N=101$

$b_{0}-b_{5}$ are unstandardized regression coefficients. $a_{1}-a_{4}$ were calculated from polynomial regression coefficients (e.g., Shanock et al. 2010). Robust standard errors are reported in parentheses

$C$ current relationship, $I$ ideal relationship, $C S$ communal sharing, $A R$ authority ranking, $E M$ equal matching, $M P$ market pricing

${ }^{\dagger} p=0.10 . * p<0.05 . * * p<0.01 . * * * p<0.001$ 
Fig. 1 Surface Charts Relating Ethical Leadership to Followers' Ideal and Current Relational Model Responses. The charts a-d relate to the relational models vignettes, while the charts $\mathbf{e}-\mathbf{h}$ relate to the relational models scale. $C S$ communal sharing, $A R$ authority ranking, $E M$ equal matching, $M P$ market pricing
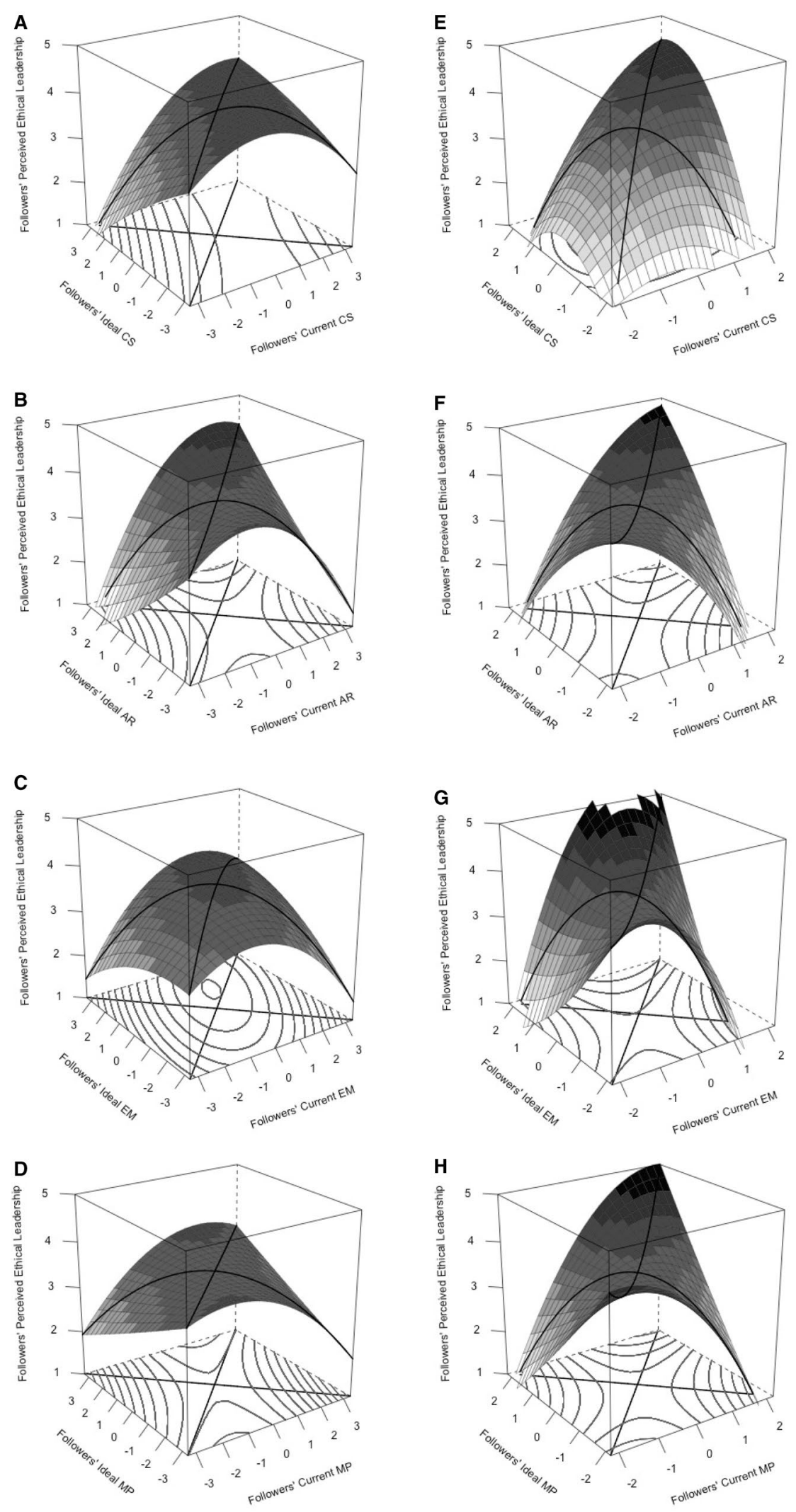
response surfaces. Accordingly, the findings in the RM vignettes support our hypothesis for CS, AR, and EM. The MP response surface showed the predicted pattern of results, but the insignificant polynomial model suggests a need for tentative interpretation. Overall, the response surfaces support our prediction: The more incongruence there is between ideal and current RMs, the less ethical leadership followers perceive. In our analysis, three of the four RMs showed the predicted incongruence effect on ethical leadership.

\section{Results for RM Scale}

Since the RM vignettes tapped each RM with one item only, we sought to conceptually replicate the hypothesized incongruence effects with an additional measure. To this end, the RM scale assessed each RM with multiple items (Vodosek 2009) while following the same analytical procedure as with the RM vignettes. We estimated polynomial regression equations for each RM. The results in Table 2 reveal that the five polynomial terms were jointly significant for each RM equation, explaining a significant amount of variance in the outcome (CS: $48 \%, p<0.001$; AR: $20 \%, p<0.001$; EM: $38 \%, p<0.001$; MP: $27 \%, p<0.001$ ).

Again, we considered the curvature slope (i.e., $a_{4}$ ) along the incongruence line (i.e., $I=-C$ ) as the key indicator of the hypothesized incongruence effect. We predicted a negative curvilinear slope along the incongruence line: Less convergence between the two predictor variables in the response surface would indicate lower perceived ethical leadership. We used unstandardized polynomial regression coefficients to calculate $a_{4}$ (Table 2). Again, the curvilinear slopes were significant and negative for each RM equation (CS: $a_{4}=-0.85, p<0.001 ;$ AR: $a_{4}=-0.78, p=0.016$; EM: $\left.a_{4}=-0.91, p<0.001 ; \mathrm{MP}: a_{4}=-0.67, p=0.025\right)$.

We then plotted the response surfaces using the estimated regression coefficients. Figure $1 \mathrm{e}-\mathrm{h}$ reveals a downward curvature along the incongruence line in each plotted response surface. Again, the level of perceived ethical leadership was lower at the front corner (i.e., $I=2$ and $C=-2$ ) and the rear corner (i.e., $I=-2$ and $C=2$ ) of the response surfaces. Accordingly, the findings in the RM scale fully support our hypothesis and supplement our findings from the RM vignettes. As predicted, all response surfaces showed lower ethical leadership levels with higher incongruence between ideal and current RMs. All RMs showed the predicted incongruence effect on ethical leadership.

\section{Discussion}

Our study is motivated by the lack of prescriptive information in Brown and colleagues' approach to ethical leadership conceptualized as "normatively appropriate conduct"
(2005, p. 120). Following from prior theorizing (Giessner and Van Quaquebeke 2010; Rai and Fiske 2011), we argue that the kinds of norms and ethical standards that followers deem appropriate depend on the particular relational context. Drawing on RMT (Fiske 1991), a prescriptive moral framework in which each of the four RMs (i.e., CS, AR, EM, and MP) implies a distinct coordination norm, our study sheds light on the norms that followers use as reference frameworks to their ethical leadership judgments. Our results revealed that followers' ethical leadership perceptions result from a fit between the RM that followers deem appropriate and the RM that they actually prescribe to their leader interactions; hence, our hypothesis was fully supported. Moreover, we found that all four RMs were relevant to the formation of followers' ethical leadership judgments. These findings are intriguing for several reasons: They underpin the normative foundation in the ethical leadership definition (Brown et al. 2005); they contextualize ethical conduct in follower-leader relationships (Giessner and Van Quaquebeke 2010; Rai and Fiske 2011), and they advise scholars against restricting ethical leadership to behavioral expectations or a communal mindset (Giessner and Van Quaquebeke 2010).

\section{Theoretical Implications}

Our study advances the ethical leadership literature in multiple ways. First, our results extend the so far limited perspective on ethical leadership regarding the number and contents of norms in Brown and colleagues' ethical leadership conception. Thus far, ethical leaders have been mainly described in communal terms reflecting CS relational standards (Giessner and Van Quaquebeke 2010). However, by applying a comprehensive and exhaustive theoretical framework of relational norms (i.e., RMT; Fiske 1991) to Brown and colleagues' (2005) ethical leadership conception, our results demonstrate that ethical leadership also exists in hierarchical (AR), egalitarian (EM), or utilitarian (MP) follower-leader relationships.

Specifically, results from the vignettes choice measure illustrate that followers did not show a particular preference regarding their ideal leader RM; their preferences were rather evenly distributed. More importantly, we modeled followers' evaluation processes and tested whether they make use of each RM normset in their leader evaluations. For each of the four RMs, we estimated statistical models using two variants of RM measures: The results support our assumptions inasmuch as all but one of the eight statistical models reached significance. All four RM normsets seem to play a role in followers' leader evaluations. Regarding the vignettes measure, CS, AR, and EM explained 18-36\% of the variance in followers' ethical leadership perceptions, whereas the four RMs in the scale measure accounted for $20-48 \%$ of 
variance. In both measures, CS explained the most variance in the outcome. This finding is not surprising, considering that some items in ELS seem conceptually closer to the relational normset of CS (e.g., "listens to what employees have to say," "has the best interests of employees in mind"; Brown et al. 2005, p. 126) than to AR, EM, or MP.

In the vignettes measure, the MP model did not explain a significant amount of variance in the outcome, although the MP response surface showed the predicted surface pattern. We assume that the non-significant finding may have derived from the response formats: Whereas the vignettes measure assessed each RM by a holistic descriptive paragraph, the scale offered a more reliable assessment of each RM through multiple items. As the MP model in the more reliable scale measure reached significance, we believe the results are trustworthy and interpret them in support of our assumption. By showing that all four relational normsets may constitute ethical leadership, we do not only address a major research gap in ethical leadership literature-namely, the lack of prescriptive information (Hannah et al. 2014; Hoch et al. 2016; Tenbrunsel and Smith-Crowe 2008)—but also demonstrate that ELS is biased toward a communal leader mindset.

Second, our study lends strong support to ethical leadership being a perceptual phenomenon rather than a set of behavioral descriptions. Behavioral descriptions promise more or less specific guidance to leaders (s. Brown et al. 2005; Kalshoven et al. 2011). However, the more specific behavioral descriptions are, the more idealistic is the image they create of an ethical leader. Largely neglecting individual and contextual differences, behavior-based ethical leadership measures are likely to miss the full complexity of the phenomenon. To account for this, Brown and colleagues (2005) chose rather unspecific behavioral descriptions and leave the definition of appropriateness to the eye of the individual beholder.

Our study closely builds on Brown and colleagues' (2005) work and investigates when followers perceive their leaders as appropriate. Based on the match-based processes suggested by ILTs, we hypothesized and consistently found for each RM that followers' ethical leadership evaluations result from a fit of their RM expectations (i.e., ideal RM) and the extent to which the RM actually rules their leader-follower interaction (i.e., current RM). Specifically, we expected lower ethical leadership scores with higher incongruence between followers' ideal and current RM. Results show consistently the predicted negative relationship in each RM model across the two variants of RM measures and therefore fully support our incongruence hypothesis. As expected, all resulting response surfaces depict a downward curvature along the incongruence line. Followers seem to hold individual, context-specific expectations regarding the coordination norm that they consider appropriate in their leader interactions. Consequently, our findings validate Brown and colleagues' (2005) relativistic view on appropriateness.

Incongruence effects do not necessarily imply that higher congruence relates to higher ethical leadership perceptions. We did not have solid theoretical ground to predict congruence effects, nor did we find any. However, we found two effects along the line of congruence that could advance theory development. In both RM measures, the slope along the congruence line (as indicated by $\mathrm{a}_{1}$ in Table 2) was significantly positive in the CS and AR surface. The slope along the congruence line depicts how perfect agreement in the predictors relates to the outcome. A positive significant slope along the congruence line means that followers' ethical leadership perceptions increase the more the predictors increase. Specifically, the more followers deem CS or AR as their ideal interaction standards and see their leaders acting accordingly, the more ethical followers will evaluate their leader interaction on average. On the other hand, the less followers deem CS or AR as their ideal interaction standards and see their leaders acting accordingly, the less ethical followers will evaluate their leaders on average. This finding is in line with the ethical leadership literature inasmuch as CS standards are reflected in caring and community-oriented leader expectations and AR standards are reflected in leaders' function as role models (Brown et al. 2005).

Third, our results extend ethical leadership literature by adding a relational nuance to the ethical leadership notion. So far, ethical leadership studies followed a rather one-sided approach describing leader behaviors (Brown et al. 2005; Kalshoven et al. 2011) or characteristics (Eisenbeiss 2012; Resick et al. 2006; Riggio et al. 2010). However, Brown and colleagues refer to ethical leadership as a "two-way communication" between follower and leader (2005, p. 120). By taking a relational perspective of normatively appropriate conduct in ethical leadership, our research studied follower-leader interaction norms. In RMT (Fiske 1991), interaction norms constitute higher-order level constructs that comprise culture-specific behavioral manifestations (Fiske 1992). They represent distinct moralities in interpersonal contact and group behaviors of similar intent. While behavioral descriptions such as "listens to what employees have to say" (ELS; Brown et al. 2005, p. 126) can be associated with $\mathrm{CS}$ as much as AR standards, the intention of the actor and its meaning for the interactant, however, differ depending on the respective reference framework. Leader characteristics follow a similar issue inasmuch as the term 'caring leader' can be descriptive of an CS as much as an AR leader. It is the form and nature of the underlying morality that prescribes meaning to the interactants, i.e., whether the leader cares for followers' needs or his/her standing in the company. Interaction norms, however, represent elementary structures of social life (Fiske 1991). 


\section{Study Strengths and Limitations}

Our study bears a number of empirical strengths. First, incongruence effects were found consistently across two RM measures. Second, we garnered a heterogeneous sample, one that represents a mix of leader and work experience while being relatively balanced for gender. As such, we have confidence in the robustness of our results. Third, we used polynomial regression analysis and reported robust errors to achieve reliable outcome predictions at each predictor combination. Finally, we closely build our rationale on Brown and colleagues' (2005) ethical leadership concept, which is at the core of most research on ethical leadership.

Granted, any discussion of our study's theoretical implications must be done in light of its limitations. First, the use of cross-sectional field data prevents us from drawing causal inferences. Based on Brown and colleagues' (2005) theory and in tandem with recent attempts to integrate social and moral psychology (Haidt 2008; Rai and Fiske 2011), we have reason to assume that followers' relational sense-making precedes ethical leader judgment. However, we cannot rule out reversed or reciprocal effects. As such, a leader with a strong or weak ethical reputation may influence the way followers construe their relationship with the leader. Future experimental and longitudinal study designs may shed further light on causation.

Second, all our data were collected through a self-report questionnaire. Hence, common method variance may have biased the correlations of our focal variables (Conway and Lance 2010). However, we were interested in incongruence effects, for which the critical indicator (i.e., the curvature slope along the incongruence line) is based on the squared term of each predictor variable and their interaction term. Thus, common method variance cannot explain our findings (McClelland and Judd 1993). If anything, it would work against finding incongruence, as survey research tends to underestimate interaction effects (Evans 1985).

Third, although the correlational patterns are in line with our expectations, some correlations between the RM vignettes and the RM scale could be expected to be slightly higher. Given the fact that we have found the expected incongruence effects across the RM measures in every RM surface, the moderate overlap between the RM measures does not threaten our results. However, this finding may have implications for the measurement of RMs in future research. As the RM scale has undergone a proper developmental process (Vodosek 2009) and has higher reliability than the vignettes measure, we advise researchers to work with and further develop the RM scale.

Furthermore, our theorizing pertains to followers' individual cognitions, which are best assessed through followers' self-reports. Other reports, such as the leader's view on the relationship with the follower, may add an interesting nuance to the study of social cognition and ethical leadership, shedding light on conflicting interpretations of the same RM (cf. Giessner and Van Quaquebeke 2010). This would result in a different research question than the one we pursued in the present study, but it nonetheless deserves further research.

Finally, while our snowballing sampling strategy resulted in a heterogeneous sample, we cannot rule out the possibility that part of the data was nested within a leader, organization, or other context variable that we did not assess. This might have influenced our data-but notably cannot account for the pattern of results. Nevertheless, future research could illuminate this matter by gathering more homogenous data, such as nested within leaders.

\section{Managerial Implications}

Although our study's primary focus was on theoretical advancement, there are critical managerial implications for a relational perspective of ethical leadership. Our findings substantiate the notion that there is more than one way to lead ethically. Hence, we advise leaders against the widespread conviction that only a communal and altruistic leader is an ethical leader. In fact, leaders run the risk of losing credibility if they act in accordance with inflicted ideals instead of their persona. Credibility is at the heart of effective leadership (Kouzes and Posner 1993) and a crucial building block in Brown and colleagues' (2005) understanding of an ethical leader.

Furthermore, our results advise leaders to engage with followers' expectations in order to be an effective ethical leader. In general, we oppose executive training formats that focus on a list of ethical behaviors. Behaviors represent brief snapshots of an interaction and should not be considered out of context. In fact, it is illusive to consider behaviors as 'one size fits all' solutions. Instead, we want to highlight that followers judge their leaders based on relational schema. RMs (Fiske 1991) are inherently fair, follow a long-term perspective, and contextualize behaviors. Specifically, we found that greater fit between followers' ideal and current RMs is more likely to be associated with ethical leadership perceptions. Thus, we strongly advise executives being trained in communication skills and relationship regulation to find and maintain ethical consensus with their followers.

On a related note, leaders who wish to take a stronger stance on business ethics need to be aware of possible misconceptions in their interactions. Leaders may be able to minimize the risk of misconceptions by understanding that the same behavior can align with different coordination norms and thus convey different ethical standards. For instance, providing detailed explanations may help to further contextualize decisions and actions. This seems especially important in times of crisis when organizations need 
to compromise between their profitability and their loyalty toward their employees. An appropriate communication method may work to acknowledge employees' wishes for comfort and loyalty while also explaining why the employer needs to deviate from the predominant coordination norm in the given situation. This way, organizations may be able to reach an explicit agreement with employees rather than violating the RM expected by followers.

Furthermore, knowing about different RMs may improve leaders' ability to read followers' behaviors and discover their expectations. In that vein, intercultural trainings are particularly relevant, especially in multi-national enterprises where trainings aim to sensitize employees to culture-dependent behavioral differences within the same RM. Newly appointed leaders may need to listen carefully to their followers, ask about critical prior experience with leaders, and pay attention to the organizational culture and its implied coordination norms. For instance, family or start-up businesses that promote a sense of community may trigger CS relationships among followers and leaders. However, companies with a strong hierarchical structure make CS relationships among followers and leaders less likely. Therefore, leaders need to be aware of the context in which they act, as organizational cultures and norms may have a strong impact on followers' expectations (Giessner and Van Quaquebeke 2010).

In sum, our investigation adds contextual nuance to the overly simplistic prescriptions for ethical leader behaviors. Contrary to prior literature, we argue that a relational approach, in which leaders actively engage with follower expectations, is of crucial importance for ethical leadership to evolve.

\section{Conclusions}

Our study findings suggest that each distinct normset in RMT (Fiske 1992) can constitute ethical leadership (Brown et al. 2005). In this way, our study extends ethical leadership literature by providing prescriptive information about the normative foundation in ethical leadership and the relational context in which those norms are considered appropriate. Our findings back up the notion that ethical leadership is a perceptual phenomenon rather than a behavioral prescription (Giessner and Van Quaquebeke 2010) and advise against narrowing ethical leaders down to a communal, altruistic mindset. We encourage future research to further investigate relational approach of ethical leadership using RMT as a contextualized moral framework.

\section{Compliance with Ethical Standards}

Conflict of interest The authors declare that there is no conflict of interest concerning this study.
Ethical approval All procedures performed in studies involving human participants were in accordance with the ethical standards of the institutional and/or national research committee and with the 1964 Helsinki declaration and its later amendments or comparable ethical standards.

Informed consent Informed consent was obtained from all individual participants included in the study.

Open Access This article is distributed under the terms of the Creative Commons Attribution 4.0 International License (http://creativeco mmons.org/licenses/by/4.0/), which permits unrestricted use, distribution, and reproduction in any medium, provided you give appropriate credit to the original author(s) and the source, provide a link to the Creative Commons license, and indicate if changes were made.

\section{References}

Adams, J. S. (1965). Inequity in social exchange. In L. Berkowitz (Ed.), Advances in experimental social psychology 2 (pp. 267-299). San Diego: Academic Press.

Bandura, A. (1977). Social learning theory. Englewood Cliffs: Prentice-Hall.

Bandura, A. (1986). Social foundations of thought and action. Englewood Cliffs: Prentice-Hall.

Bass, B. M. (1985). Leadership and performance beyond expectations. New York: Free Press.

Bedi, A., Alpaslan, C. M., \& Green, S. (2016). A meta-analytic review of ethical leadership outcomes and moderators. Journal of Business Ethics, 139(3), 517-536. https://doi.org/10.1007/s1055 1-015-2625-1.

Blum, L. (1987). Particularity and responsiveness. In J. Kagan \& $\mathrm{S}$. Lamb (Eds.), The emergence of morality in young children (pp. 437-446). Chicago: University of Chicago Press.

Brislin, R. W. (1970). Back-translation for cross-cultural research. Journal of Cross-Cultural Psychology, 1(3), 185-216. https:// doi.org/10.1177/135910457000100301.

Brown, M. E., \& Treviño, L. K. (2006). Ethical leadership: A review and future directions. The Leadership Quarterly, 17(6), 595-616. https://doi.org/10.1016/j.leaqua.2006.10.004.

Brown, M. E., Treviño, L. K., \& Harrison, D. A. (2005). Ethical leadership: A social learning perspective for construct development and testing. Organizational Behavior and Human Decision Processes, 97(2), 117-134. https://doi.org/10.1016/j.obhdp.2005.03.002.

Burns, J. M. (1978). Leadership. New York: Harper \& Row.

Ciulla, J. B. (1995). Leadership ethics: Mapping the territory. Business Ethics Quarterly, 5(1), 5-28. https://doi.org/10.2307/3857269.

Connelley, D. L., \& Folger, R. (2004). Hidden bias: The impact of relational models on perceptions of fairness in human resource systems. In Relational models theory: A contemporary overview (pp. 197-220). Mahwah: Erlbaum.

Conway, J. M., \& Lance, C. E. (2010). What reviewers should expect from authors regarding common method bias in organizational research. Journal of Business and Psychology, 25(3), 325-334. https://doi.org/10.1007/s10869-010-9181-6.

Edwards, J. R. (2002). Alternatives to difference scores. Polynomial regression analysis and response surface methodology. In F. Drasgow \& N. W. Schmitt (Eds.), Advances in measurement and data analysis (pp. 350-400). San Francisco: Jossey-Bass.

Edwards, J. R., \& Parry, M. E. (1993). On the use of polynomial regression equations as an alternative to difference scores in organizational research. Academy of Management Journal, 36(6), 15771613. https://doi.org/10.2307/256822. 
Eisenbeiss, S. A. (2012). Re-thinking ethical leadership: An interdisciplinary integrative approach. The Leadership Quarterly, 23(5), 791-808. https://doi.org/10.1016/j.leaqua.2012.03.001.

Eisenbeiss, S. A., van Knippenberg, D., \& Fahrbach, C. M. (2014). Doing well by doing good? Analyzing the relationship between CEO ethical leadership and firm performance. Journal of Business Ethics, 128(3), 635-651. https://doi.org/10.1007/s1055 1-014-2124-9.

Evans, M. G. (1985). A Monte Carlo study of the effects of correlated method variance in moderated multiple regression analysis. Organizational Behavior and Human Decision Processes, 36(3), 305-323. https://doi.org/10.1016/0749-5978(85)90002-0.

Fiddick, L., \& Cummins, D. (2007). Are perceptions of fairness relationship-specific? The case of noblesse oblige. The Quarterly Journal Of Experimental Psychology, 60(1), 16-31. https://doi. org/10.1080/17470210600577266.

Fiske, A. P. (1991). Structures of social life: The four elementary forms of human relations. New York: Free Press.

Fiske, A. P. (1992). The four elementary forms of sociality: Framework for a unified theory of social relations. Psychological Review, 99(4), 689-723. https://doi. org/10.1037/0033-295x.99.4.689.

Fiske, A. P., and Haslam, N. (1997). The structure of social substitutions: A test of relational models theory. European Journal of Social Psychology, 27.6., 725-729. https://doi.org/10.1002/ (SICI) 1099-0992(19971 1/12)27:6\%3C725 ::AID-EJSP8 32\%3E3.0.CO;2-A

Fiske, A. P., \& Haslam, N. (2005). The four basic social bonds: Structures for coordinating interaction. In M. W. Baldwin (Ed.), Interpersonal Cognition (pp. 267-298). New York: The Guilford Press.

Fiske, A. P., Haslam, N., \& Fiske, S. T. (1991). Confusing one person with another: What errors reveal about the elementary forms of social relations. Journal of Personality and Social Psychology, 60(5), 656-674. https://doi.org/10.1037//0022-3514.60.5.656.

Foti, R. J., Hansbrough, T. K., Epitropaki, O., \& Coyle, P. T. (2017). Dynamic viewpoints on implicit leadership and followership theories: Approaches, findings, and future directions. The Leadership Quarterly, 25(2), 411-412. https://doi.org/10.1016/j.leaqu a.2014.02.004

Foti, R. J., \& Lord, R. G. (1987). Prototypes and scripts: The effects of alternative methods of processing information on rating accuracy. Organizational Behavior and Human Decision Processes, 39(3), 318-340. https://doi.org/10.1016/0749-5978(87)90027-6.

Giessner, S., \& Van Quaquebeke, N. (2010). Using a relational models perspective to understand normatively appropriate conduct in ethical leadership. Journal of Business Ethics, 95(S1), 43-55. https:// doi.org/10.1007/s10551-011-0790-4.

Gilligan, C. (1982). In a different voice: Psychological theory and women's development. Cambridge: Harvard University Press.

Gini, A. (1997). Moral leadership and business ethics. The Journal of Leadership Studies, 4(4), 64-81. https://doi.org/10.1177/10717 9199700400406.

Goodnow, J. J. (1998). Beyond the overall balance: The significance of particular tasks and procedures for perceptions of fairness in household work distributions. Social Justice Research, 11(3), 359-376. https://doi.org/10.1023/a:1023295018444.

Gouldner, A. W. (1960). The norm of reciprocity: A preliminary statement. American Sociological Review, 25, 161-178. https://doi. org/10.2307/2092623.

Greenleaf, R. K. (1977). Servant leadership: A journey into the nature of legitimate power and greatness. Mahwah: Paulist Press.

Guth, W., Schmittberger, R., \& Schwartz, R. (1982). An experimental analysis of ultimatum bargaining. Journal of Economic Behavior and Organization, 3(4), 367-388. https://doi.org/10.1016/01672681(82)90011-7.
Haidt, J. (2008). Morality. Perspectives on Psychological Science, 3(1), 65-72. https://doi.org/10.1177/0956797611403.

Hamilton, V. L. (1978). Who is responsible? Toward a social psychology of responsibility attribution. Social Psychology, 41(4), 316-328. https://doi.org/10.2307/3033584.

Hannah, S. T., Sumanth, J. J., Lester, P., \& Cavarretta, F. (2014). Debunking the false dichotomy of leadership idealism and pragmatism: Critical evaluation and support of newer genre leadership theories. Journal of Organizational Behavior, 35(5), 598-621. https://doi.org/10.1002/job1931.

Haslam, N. (2004). Research on the relational models: An overview. In Relational models theory - A contemporary overview (pp. 27-57). https://doi.org/10.4324/9781410611413.

Haslam, N., \& Fiske, A. P. (1992). Implicit relationship prototypes: Investigating five theories of the cognitive organization of social relationships. Journal of Experimental Social Psychology, 28(5), 441-474. https://doi.org/10.1016/0022-1031(92)90041-H.

Hernandez, M., \& Sitkin, S. B. (2012). Who is leading the leader? Follower influence of leader ethicality. In D. De Cremer \& A. E. Tenbrunsel (Eds.), Behavioral business ethics: Shaping an emerging field (pp. 81-104). New York: Routledge.

Hoch, J. E., Bommer, W. H., Dulebohn, J. H., \& Wu, D. (2016). Do ethical, authentic, and servant leadership explain variance above and beyond transformational leadership? A meta-analysis. Journal of Management. https://doi.org/10.1177/0149206316 665461.

Huang, X., Wright, R. P., Chiu, W. C., \& Wang, C. (2008). Relational schemas as sources of evaluation and misevaluation of leader-member exchanges: Some initial evidence. The Leadership Quarterly, 19(3), 266-282. https://doi.org/10.1016/j.leaqu a.2008.03.003.

Kalshoven, K., Den Hartog, D. N., \& De Hoogh, A. H. B. (2011). Ethical leadership at work questionnaire (ELW): Development and validation of a multidimensional measure. The Leadership Quarterly, 22(1), 51-69. https://doi.org/10.1016/j.leaqu a.2010.12.007.

Kouzes, J. M., \& Posner, B. Z. (1993). Credibility: How leaders gain and lose it, why people demand it. San Francisco: Jossey-Bass.

Liden, R. C., Wayne, S. J., Zhao, H., \& Henderson, D. (2008). Servant leadership: Development of a multidimensional measure and multi-level assessment. The Leadership Quarterly, 19(2), 161177. https://doi.org/10.1016/j.leaqua.2008.01.006.

Lord, R. G., Foti, R. J., \& De Vader, C. L. (1984). A test of leadership categorization theory: Internal structure, information processing, and leadership perceptions. Organizational Behavior and Human Performance, 34(3), 343-378. https://doi.org/10.1016/00305073(84)90043-6.

Lord, R. G., \& Maher, K. J. (2002). Leadership and information processing: Linking perceptions and performance. New York: Routledge. (Original work published 1991).

Lord, R. G., \& Shondrick, S. J. (2011). Leadership and knowledge: Symbolic, connectionist, and embodied perspectives. The Leadership Quarterly, 22(1), 207-222. https://doi.org/10.1016/j.leaqu a.2010.12.016.

Mayer, D. M., Kuenzi, M., Greenbaum, R., Bardes, M., \& Salvador, R. (2009). How low does ethical leadership flow? Test of a trickle-down model. Organizational Behavior and Human Decision Processes, 108(1), 1-13. https://doi.org/10.1016/j.obhdp 2008.04.002.

McClelland, D. C. (1976). The achieving society. New York: Wiley. (Original work published 1961).

McClelland, G. H., \& Judd, C. M. (1993). Statistical difficulties of detecting interactions and moderator effects. Psychological Bulletin, 114, 376-390. https://doi.org/10.1037/0033-2909.114.2.376.

Meindl, J. R. (1995). The romance of leadership as a follower-centric theory: A social constructionist approach. The Leadership 
Quarterly, 6(3), 329-341. https://doi.org/10.1016/10489843(95)90012-8.

Morgeson, F. P., \& Humphrey, S. E. (2006). The Work Design Questionnaire (WDQ): Developing and validating a comprehensive measure for assessing job design and the nature of work. Journal of Applied Psychology, 91(6), 1321. https://doi. org/10.1037/0021-9010.91.6.1321.

Mukherjee, A. S. (2016, December 28). Why we're seeing so many corporate scandals. Harvard Business Review. Retrieved from https://www.hbr.org.

Ng, T. W. H., \& Feldman, D. C. (2015). Ethical leadership: Metaanalytic evidence of criterion-related and incremental validity. Journal of Applied Psychology, 100(3), 948-965. https://doi. org/10.1037/a0038246.

Northouse, P. G. (2010). Leadership: Theory and practice (5th edn.). Thousand Oaks: Sage.

Parsons, T., \& Shils, E. A. (1951). Values, motives, and systems of action. In T. Parsons \& E. A. Shils (Eds.), Toward a general theory of action (pp. 47-275). New York: Harvard University Press.

Piaget, J. (1973). Le jugement moral chez lenfant [The moral judgment of the child]. (Bibliotheque de Philosophic Contemporaine). Paris: Presses Universitaires de France. (Original work published 1932).

Power, F. C., Higgins, A., \& Kohlberg, L. (1989). The habit of the common life: Building character through just community schools. In L. Nucci (Ed.), Moral development and character education: A dialogue (pp. 125-143). Berkeley: McCutchan.

Rai, T. S., \& Fiske, A. P. (2011). Moral psychology is relationship regulation: Moral motives for unity, hierarchy, equality, and proportionality. Psychological Review, 118(1), 57-75. https://doi. org/10.1037/a0021867.

Rawls, J. (1971). A theory of justice. Cambridge: Belknap Press.

Resick, C. J., Hanges, P. J., Dickson, M. W., \& Mitchelson, J. K. (2006). A cross-cultural examination of the endorsement of ethical leadership. Journal of Business Ethics, 63(4), 345-359. https ://doi.org/10.1007/s10551-005-3242-1.

Riggio, R. E., Zhu, W., Reina, C., \& Maroosis, J. A. (2010). Virtuebased measurement of ethical leadership: The Leadership Virtues Questionnaire. Consulting Psychology Journal: Practice and Research, 62(4), 235-250. https://doi.org/10.1037/a0022286.

Schönbrodt, F. D. (2015). RSA: An R package for response surface analysis. Retrieved from https://cran.r-project.org.

Selznick, P. (1992). The moral commonwealth: Social theory and the promise of community. Berkeley: University of California Press.

Shanock, L. R., Baran, B. E., Gentry, W. A., Pattison, S. C., \& Heggestad, E. D. (2010). Polynomial regression with response surface analysis: A powerful approach for examining moderation and overcoming limitations of difference scores. Journal of Business and Psychology, 25(4), 543-554. https://doi.org/10.1007/s1086 9-010-9183-4.

Sherman, L. (2017, March 13). Why boards must step up to deter corporate scandals. Forbes. Retrieved from https://www.forbes.com.

Tajfel, H.. (Ed.). (1982). Social identity and intergroup relations: European studies in social psychology. Cambridge: Cambridge University Press.

Tenbrunsel, A. E., \& Smith-Crowe, K. (2008). Ethical decision making: Where we've been and where we're going. The Academy of Management Annals, 2(1), 545-607. https://doi.org/10.1080/19416 520802211677.

Tindale, R. S., \& Davis, J. H. (1985). Individual and group reward allocation decisions in two situational contexts: Effects of relative need and performance. Journal of Personality and Social Psychology, 48(5), 1146-1161. https://doi. org/10.1037/0022-3514.48.5.1148.b.

Toffler, B. L. (1986). Tough choices: Managers talk ethics. Hoboken: Wiley.

Trevino, L. K., Brown, M., \& Hartman, L. P. (2003). A qualitative investigation of perceived executive ethical leadership: Perceptions from inside and outside the executive suite. Human Relations, 56(1), 5-37. https://doi.org/10.1177/001872670305600 1448.

van Gils, S., van Quaquebeke, N., \& van Knippenberg, D. (2010). The $\mathrm{X}$-factor: On the relevance of implicit leadership and followership theories for leader-member exchange agreement. European Journal of Work and Organizational Psychology, 19(3), 333-363. https://doi.org/10.1080/13594320902978458.

Van Quaquebeke, N., Graf, M. M., \& Eckloff, T. (2014). What do leaders have to live up to? Contrasting the effects of central tendency versus ideal-based leader prototypes in leader categorization processes. Leadership, 10(2), 191-217. https://doi.org/10.1177/17427 15013476081.

Vodosek, M. (2009). The relationship between relational models and individualism and collectivism: Evidence from culturally diverse work groups. International Journal of Psychology, 44(2), 120128. https://doi.org/10.1080/00207590701545684.

Weber, M. (1978). Economy and society (G. Roth \& C. Wittich, Trans.). Berkeley: University of California Press. (Original work published 1922).

Yukl, G. (2002). Leadership in organizations (5th edn.). Upper Saddle River: Prentice Hall.

Zapata, C. P., Olsen, J. E., \& Martins, L. L. (2013). Social exchange from the supervisor's perspective: Employee trustworthiness as a predictor of interpersonal and informational justice. Organizational Behavior and Human Decision Processes, 121(1), 1-12. https://doi.org/10.1016/j.obhdp.2012.11.001. 